\title{
CONSIDERAÇÕES SOBRE A ESFERA PÚBLICA TECNOLÓGICA: UMA APROXIMAÇÃO COM A TEORIA DE JÜRGEN HABERMAS
}

\author{
Carlos André Maciel Pinheiro Pereira* \\ Ricardo Tinoco de Góes**
}

\begin{tabular}{l|l}
\hline RECEBIDO EM: & 21.5.2020 \\
\hline APROVADO EM: & $\mathbf{2 2 . 2 . 2 0 2 1}$ \\
\hline
\end{tabular}

* Doutorando em Filosofia do Direito pela Universidade Federal de Pernambuco (UFPE). Mestre em Direito Constitucional pela Universidade Federal do Rio Grande do Norte (UFRN), especialista em Direito Tributário pelo Instituto Brasileiro de Estudos Tributários (Ibet) e bacharel em Direito pelo Centro Universitário do Rio Grande do Norte (UNI-RN). Professor DNS I da Universidade Potiguar (UnP) e advogado. E-mail: candremaciel@hotmail.com

** Doutor em Filosofia do Direito pela Pontifícia Universidade Católica (PUC-SP), mestre em Direito Constitucional e bacharel em Direito pela Universidade Federal do Rio Grande do Norte (UFRN). Professor adjunto (UFRN) e juiz de Direito do Tribunal de Justiça do Rio Grande do Norte (TJRN). E-mail: ricardotinoco@tjrn.jus.br 
- RESUMO: Este artigo tem como objetivo discutir o uso das redes sociais, enquanto esfera pública tecnológica, à luz da teoria de Jürgen Habermas, tendo como justificativa o atual panorama político vivenciado no Brasil e no mundo. Utiliza o método indutivo em sua totalidade e o método dialético para sintetizar críticas deferidas à obra de Habermas. Compreende-se que a esfera pública é um elemento intrínseco à cidadania contemporânea ao permitir um diálogo ativo entre o Estado e a sociedade civil que pode ser manifestado por meio das redes sociais, as quais tem o potencial dialógico, a despeito da existência das notícias falsas e dos dissensos que podem surgir do pluralismo. Ao final, conclui-se que a esfera pública tecnológica é um direito político fundamental. PALAVRAS-CHAVE: Jürgen Habermas; esfera pública; esfera pública tecnológica; redes sociais.

\section{CONSIDERATIONS ON THE TECHNOLOGICAL PUBLIC} SPHERE: AN APPROACH WITH JÜRGEN HABERMAS'S THEORY

- abstract: This article aims to discuss the use of social networks as an public sphere in the light of Jürgen Habermas's theory, having as justification the current political landscape experienced in Brazil and in the world. It employs the inductive method in its totality and dialectical method into the synthesis criticisms deferred to the work of Habermas. It understands that the public sphere is an intrinsic element to contemporary citizenship because it allows an active dialogue between the State and the civil society. It understands that the public sphere can be manifested through social networks, which have a lot of dialogical potential, despite the existence of fake news and the dissent that can arise from pluralism. In the end, it concludes that the technological public sphere is a fundamental political right.

- KEYwords: Jürgen Habermas; public sphere; technological public sphere; social networks. 


\section{Introdução}

As redes sociais dão voz a milhares de cidadãos, ainda que tornem o planejamento de longo prazo algo difícil, formando um desafio para as futuras gerações políticas. Através delas, tem-se constantes referendos sobre a atividade legislativa. Como exemplo, podem ser citados os presidentes norte-americanos Barack Obama e Donald Trump, que mantêm intensa atividade no $T$ witter. De igual maneira, Justin Trudeau, presidente do Canadá, participa das redes sociais, com a finalidade de se comunicar com o eleitor como forma de accountability, fazendo uma prestação de contas daquilo que está sendo feito em sua gestão. No Brasil, o presidente Jair Bolsonaro utilizou as redes sociais ao longo da campanha presidencial de 2018 e permanece utilizando as plataformas midiáticas para lançar suas considerações e seus projetos.

Esse cenário gera inquietação teórica, uma vez que existem autores no âmbito da filosofia política e da filosofia do direito que tratam da interlocução entre representantes e representados. Considerando o panorama acima, cabe questionar de que maneira os autores abordam a questão da esfera pública e sua possível correlação com o emprego da tecnologia na consecução da democracia. É nesse afã que o presente artigo será desenvolvido, objetivando analisar, no viés qualitativo, a abordagem empregada pelos autores sobre a temática, situando-se em referenciais bibliográficos. Em termos metodológicos, empregará o método indutivo, para inferir a possível correlação entre esfera pública e tecnologia, bem como o método dialético, no que cinge ao diálogo entre os autores, com destaque para o emprego da teoria de Jürgen Habermas.

Na primeira seção, o estudo contemplará a evolução histórica da esfera pública, a partir da Grécia antiga para o Iluminismo, com esteio nas observações de Hannah Arendt e Jürgen Habermas, além de sinalizar qual eixo acopla a democracia e a figura da esfera pública. No item subsequente, a esfera pública será discutida como elemento da cidadania ativa, de acordo com o conceito de autonomia política e dos princípios discursivos de Habermas. No último tópico, serão tratadas as críticas ao pensamento habermasiano e traçado o devido paralelo com o potencial tecnológico das redes sociais. 


\section{Uma breve evolução histórico-teórica da esfera pública}

A cidadania é um elemento-chave para debater a democracia deliberativa, pois o cidadão, enquanto membro de uma sociedade organizada, é o destinatário de toda a produção administrativa do Estado. Trata-se de uma relação multifacetária baseada nos direitos fundamentais: o sujeito tem um âmbito de proteção contra intervenções estatais arbitrárias, é credor de políticas públicas que concretizem garantias constitucionais e, por fim, pode influenciar a formação estrutural do Estado a partir do uso dos direitos políticos. ${ }^{1}$

De fato, o povo-cidadão deve ser um sujeito político ativo que serve de ponto de partida para a legitimidade estatal, consoante que em "última instância estarem governando" os rumos do estado democrático ${ }^{2}$ a partir da autodeterminação. Isso significa que a fundamentação do Estado é baseada na "totalidade do povo atingindo pelas normas”, de modo bem mais amplo que a simples consagração de um eleito pela democracia representativa (MÜLLER, 2003, p. 57-58).

Daí buscar uma compreensão da esfera pública enquanto estrato identificador das atividades cotidianas que podem ser lançadas no arranjo comunicativo, para fazer uma construção argumentativa que parta de questões preliminarmente particulares para terminar em assuntos políticos. Aí está a justificativa deste estudo quanto a opção da democracia deliberativa, consoante será exposto e aprofundado nas seções que seguem.

Para seguir nessa vertente de filosofia normativa, ${ }^{3}$ a primeira ação a ser feita é entender o significado que deve ser atribuído ao termo "público". O vocábulo refere-se a dar publicidade, tornar algo público, permitir que o sujeito forme uma opinião sobre determinado tema, não se confundindo com a acepção de "público-estatal", que pode ser utilizada para tratar do poder público do Estado (HABERMAS, 2014, p. 94-95).

1 Essa descrição é tratada por Leonardo Martins e Dimitri Dimoulis (2012, p. 53) a partir da classificação dada por Georg Jellinek às espécies de direitos fundamentais. O desenvolvimento dado por estes autores à questão permite identificar essa dinâmica entre sujeito-cidadão e Estado-poder.

2 Tal observação é consignada na obra de Friedrich Müller (2003, p. 46), que complementa dizendo que o termo democracia deriva etimologicamente da palavra povo.

3 O termo filosofia normativa designa um estudo que está inserido no âmbito de um dever ser. É que as proposições a serem lançadas terão caráter deontológico, para servir de parâmetro a partir do qual a sociedade pode e deve se basear. De mais a mais, optar pela democracia deliberativa significa assumir uma instância que se inicia na filosófica política com desdobramentos para a atividade jurídica, conferindo a este estudo um viés jusfilosófico. 
A própria noção de comunhão comunicativa em torno de questões da coletividade é algo inato à natureza do homem. Como diz Hannah Arendt: "Nenhuma vida humana [...] é possível sem um mundo que, direta ou indiretamente, testemunhe a presença de outros seres humanos” (ARENDT, 2007, p. 31).

A esfera pública do período clássico representava a liberdade de não estar subjugado a nenhuma servidão, dentro da qual os pares iguais ${ }^{4}$ digladiavam entre si para firmar sua individualidade - e superioridade - em relação aos demais (ARENDT, 2007, p.41-51). E, nessas atividades, os diálogos entre os cidadãos livres ocorriam na forma de conselho ou tribunal, sem necessariamente ter vinculação a um local específico, onde a razão maior era ser consagrado vencedor do debate (HABERMAS, 2014, p. 96-97).

Se no período medieval a esfera pública ficou impregnada pela homogeneidade da religiosidade cristã, com a ascensão da burguesia, a cisão entre vida pública e privada leva a um novo ambiente profícuo para a abordagem de questões comuns aos homens. ${ }^{5}$ Historicamente, o período de retomada do espaço público ocorre com as revoluções francesa e americana (BENHABIB, 1992, p. 75).

A força motriz desse novo paradigma repousa na fungibilidade da propriedade. É que as coisas vão perdendo gradualmente seu caráter imóvel e se transformam em móveis, consumíveis, sendo a propriedade originária da atividade humana. Trata-se da origem e finalidade. Não obstante, a propriedade também remete aos limites que separam o público e o privado, de modo que, no núcleo de sua propriedade, o homem retém sua individualidade e privacidade, sendo um abrigo para a publicidade do mundo público (ARENDT, 2007, p. 78-82).

A esfera pública liberal ${ }^{6}$ vem colher elementos que subsidiam a legitimidade política de uma deliberação contida em amarras de ordem moral e política. A epistemologia dessa circunscrição remonta à ideia de bem, objeto do debate entre poder público e indivíduo: o debate é restrito para divergências quanto à concepção de bem a ser adotada, em especial quando o Estado diverge da sociedade.

O problema desse tipo de esfera é que seu desdobramento recai na exclusão de grupos não expressos no jogo político majoritário, ou ainda que não perfilhem da posição

$4 \quad$ Na Grécia antiga, os cidadãos iguais e livres eram aqueles que detinham alguma espécie de riqueza e que por tal razão podiam se dedicar a atividade política (HABERMAS, 2014, p. 96).

5 Habermas (2014, p. 101) comenta que o feudalismo da idade média continha uma esfera pública no sentido de ofertar publicidade aos atos reais, servindo como instrumento de representação pública da dominação. Não se mostra, pois, como uma esfera verdadeiramente social, mas sim como uma instituição representativa.

6 Considerar a acepção liberal no contexto do Iluminismo. 
vencedora. Na verdade, o próprio debate em si com o Estado sobre qual entendimento deve prevalecer demonstra por si só um paternalismo legal, consequência imediata da exacerbação do liberalismo. Em outro vértice, também não se pode admitir uma esfera pública exclusivamente comunitarista, pois iria descambar em uma piora da situação desses grupos.

É que o paternalismo legal e a ditadura da maioria são consequências do superdimensionamento de uma das autonomias do cidadão. Quando o liberalismo amplia a autonomia privada, tem-se o paternalismo legal, quando o Estado entende melhor as necessidades do que o próprio sujeito. Por outro lado, a ditadura da maioria decorre do alargamento da autonomia pública, fulminando as manifestações políticas dos grupos minoritários (SILVA, 2008, p. 96-99). Com efeito, a opção deste estudo é por uma autonomia política calcada na atividade comunicativa, de modo que tanto o âmbito privado quanto o público fiquem dimensionados na exata medida para proporcionar consensos entre os cidadãos.

De posse desse conhecimento, o próximo item discutirá a solução trazida por Jürgen Habermas para os dois problemas apontados acima.

\section{A esfera pública como elemento da cidadania ativa na teoria de Jürgen Habermas}

A esfera pública tem o potencial para enlaçar fortes aspectos democráticos, permitindo uma interlocução ativa do cidadão com o Estado. A problemática desse instituto reside no destaque para qual autonomia será dada ênfase: autonomia pública ou autonomia privada. Como uma alternativa para uma esfera pública verdadeiramente democrática, Habermas propugna um arquétipo de autonomia política que visa a resguardar o próprio cidadão, pois reconhece que todas as autonomias privadas são iguais e estão submetidas a uma estrutura comunicativa no âmbito da autonomia pública. Na verdade, o cidadão se torna autor da norma da qual é destinatário(HABERMAS, 2002, p. 86-87).

Nesse desiderato, o estudo retém a esfera pública como elemento intrínseco ao exercício da cidadania, dado que é a arena onde ocorrem as deliberações políticas. É que o exercício comunicativo repercute um espaço social no qual os sujeitos podem alcançar entendimentos sobre fatos concretos do mundo que os circunda (HABERMAS, 1997a, p. 92). 
No exercício dessa atividade comunicativa é que as necessidades, os problemas e suas respectivas soluções - da comunidade são identificados e aptos a serem projetados para o crivo do poder público, fazendo com que aquele grupo se transforme em coautor da norma. ${ }^{7}$ Trata-se de um mecanismo para maximizar a eficácia dos direitos fundamentais envolvidos, bem como lastrear democraticamente a produção legislativa. ${ }^{8}$

Por não estarem restritas a qualquer metáfora arquitetônica, as esferas públicas ocorrem nos mais diversos âmbitos: de conversas triviais que evoluem para a problemática política-social, desembocando até mesmo nas redes sociais, atual arena de debates da sociedade contemporânea (HABERMAS, 1997a, p. 93-98).

Habermas reconhece a interação entre a esfera pública e o poder público a partir do percurso assumido pelo fluxo comunicativo, tendo início nas esferas públicas informais e periféricas até adentrar pelas comportas da esfera pública formal e política, consubstanciada no complexo público que compreende parlamento, tribunal e administração implementadora, ${ }^{9}$ fazendo valer o caráter procedimental da democracia (HABERMAS, 1997b, p. 88-89).

Não obstante, Habermas complementa que a esfera pública é composta, enquanto rede comunicativa na sociedade civil, pelas associações e organizações que são livres, sem caráter econômico e que não são estatais e é através destas que a sociedade desempenha sua atividade comunicativa, no afã de solucionar as questões de interesse geral (HABERMAS, 1997b, p. 99).

Contrapondo a construção habermasiana, Nancy Fraser (1992, p. 110-111) pretende ir para além do declínio da esfera pública liberal e ampliar os horizontes da esfera pública deliberativa, oxigenando o modelo democrático. ${ }^{10}$ Fraser considera que o

7 Convém pensar tanto na máxima do princípio do discurso, instituído por Habermas que aduz o serem "válidas as normas de ação às quais todos os possíveis atingidos poderiam dar o seu assentimento, na qualidade de participantes de discursos racionais.” Outrossim, esse princípio explica como as normas - morais ou jurídicas - podem ser fundamentadas de maneira imparcial pelo arranjo comunicativo (HABERMAS, 1997a, p. 142-143).

8 A noção de maximização pode ser encontrada na teoria de Peter Häberle (2002, p. 38), cujos postulados se coaduanam com a posição aqui defendida. O referido autor não só considera que a democracia do cidadão, baseada na identidade dos direitos fundamentais, é mais apropriada que aquela soberania estrita, que advém do exercício da democracia representativa. De mais a mais, a base de Häberle (2002, p. 15) subjaz no reconhecimento do destinatário da norma enquanto sujeito ativo do processo hermenêutico, consoante este ser aquele que de fato viverá os efeitos da norma. Apesar de Häberle estar debruçado sobre a hermenêutica constitucional, não há dúvidas de sua filia procedimental e comprometimento com um modelo de democracia baseada na participação do cidadão.

9 Fazendo equivalência para a nomenclatura utilizada pela Constituição Federal, tem-se respectivamente: legislativo, judiciário e executivo.

10 A autora explica que Habermas opta por fazer um corte histórico da ascensão e declínio da esfera pública liberal ou burguesa - na obra Mudança estrutural da esfera pública. Daí que Fraser acha interessante desenvolver uma teoria 
modelo tratado por Habermas possui uma pecha burguesa e machista, que assume os indivíduos como iguais - contudo, sem alicerçar a igualdade como um requisito fundamental do debate ${ }^{11}$.

Outras observações trazidas pela autora são o suposto afastamento causado pelo pluralismo; a restrição da esfera pública para assuntos públicos - ficando os privados sem relevância ${ }^{12}$ - e que a existência da esfera pública pressupõe uma cisma entre sociedade civil e Estado (FRASER, 1992, p. 117-118). A chave para a correlação da esfera pública e a soluções das questões apontadas por Fraser está no aparato tecnológico dentro do qual as sociedades contemporâneas estão inseridas. Por isso, não há dúvidas que a facilidade de comunicação e obtenção de informações permite a ampliação dos debates, razão pela qual o próximo tópico irá discutir os contornos de uma esfera pública virtual.

\title{
4. A democracia deliberativa na esfera pública virtual
}

\author{
Como o processo deliberativo tem uma dupla dimensão, o cidadão fica no centro do \\ protagonismo da atividade comunicativa. A primeira dimensão diz respeito ao campo \\ privado do indivíduo, que encontra argumentos para validar sua tomada de posições.
}

pós-burguesa para a esfera pública (FRASER, 1992, p. 110-111). Ainda que a matriz teórica habermasiana seja adotada, é produtivo para esta empreitada buscar complementações ao assunto sem perder de mira a veia discursiva que se intenta fazer presente na tese aqui exposta.

11 Cabe aqui refutar, ainda que indiretamente, pois não cinge ao escopo deste estudo, o comentário da autora: Habermas contempla uma situação ideal de fala que traz uma preocupação de ordem comunicativa: as pessoas devem ter iguais chances de falar, ouvir e se entender. Para haver uma equiparação na atividade deliberativa é implícito que uma igualdade material se faz também necessária. Sobre a situação ideal de fala, quatro são seus componentes: "(1) Todos os potenciais participantes do discurso devem dispor de iguais chance de proferir atos de fala, de tal modo que possam colocar questões e oferecer respostas livremente. (2) Todos devem possuir igual chance de fazer interpretações, afirmações, sugestões, esclarecimentos e justificações e problematizar as pretensões de validade das mesmas, de modo que nenhum preconceito permaneça imune a críticas. (3) São admitidos no discurso apenas os falantes que, enquanto agentes, possuam igual chance de empregar atos de fala, ou seja, de expressas suas posições, sentimentos e intenções. (4) São admitidos no discurso apenas os falantes que, enquanto agentes, possuam igual chance de empregar atos de falas regulativos, ou seja, de dar e recusar ordens, permitir e proibir, prometer e negar promessas etc" (SEGATTO, 2008, p. 47).

12 Novamente, em resposta a Fraser, não é que assuntos privados sejam impossíveis de serem tratados no âmbito público. A ideia de esfera pública trazida por Habermas repousa na trivialidade: são assuntos comuns e privados que ressoam através do compartilhamento comunicativo. Aliás, a premissa de um compartilhamento comunicativo trazido a rebote pela intersubjetividade, marca presente no pensamento de Habermas, faz com que inevitavelmente assuntos de ordem privada venham à tona. Vale a pena pensar aqui no caráter cíclico, no viés fenomenológico, de que o que emana da esfera pública irá voltar ao âmbito privado, nos termos do cidadão ser autor e destinatário da norma. De mais a mais, o conceito desenhado por Habermas da esfera pública como caixa de ressonância - e que já foi exposto acima - consegue responder ao questionamento em tela. 
Já a dimensão pública ou coletiva decorre deste compartilhamento comum de informações: a deliberação de todos é um intercâmbio de informações e aprendizado, pois o cidadão se torna apto a perceber suas idiossincrasias e quais efeitos estas suscitam na sua vida individual e coletiva, o que finda, inevitavelmente, trazendo à tona problemas e soluções que não foram percebidas antes (MANIN, 2007, p. 30-32).

Logo, o cidadão, quando fica imerso em uma esfera pública tecnológica que propicia o contato com diversas outras biografias privadas, torna a perceber quais problemas compartilha com seus pares e de que maneiras podem ser solucionados. A esfera pública é, em última análise, um eficiente mecanismo para identificação de necessidades normativas de uma coletividade. ${ }^{13}$

A relação entre tecnologia, internet e sociedade civil resulta na chamada sociedade da informação, que rompe com os ditames da mídia de massas e propõe novos modelos midiáticos. ${ }^{14}$ Afinal, o advento da internet modificou toda a sistemática das comunicações contemporâneas, abrindo novos nichos e ampliando a esfera pública tradicional para níveis de problematizações globais. Isso se reflete até mesmo no Brasil, que, desde os anos 2000, vivencia larga expansão no acesso à rede mundial de computadores (BLOTA, 2013, p. 209-210). Mesmo com os riscos de opacidade e empobrecimento da comunicação ${ }^{15}$, trata-se mais de pensar em ajuste nos termos de encontrar informações que sejam efetivamente relevantes. ${ }^{16}$ Ademais, uma esfera pública minimamente organizada em como filtrar os elementos insignificantes para a sua assembleia. ${ }^{17}$

13 Por coletividade se entende a reunião de cidadãos orientados a um objetivo comum, sem estar necessariamente vinculado a um movimento social filiado a uma corrente ideológica político-partidiária específica. Todavia, esta concepção não exclui de qualquer forma a manifestação desses setores. O que se intenta é um diálogo entre cidadania mobilizada e o estamento político.

14 As redes sociais são um exemplo dessas novas mídias que se afastam da mass media, cuja principal finalidade élucrar com o entretenimento e a informação, permitindo a emancipação do usuário (OLIVEIRA, 2012, p. 223). Surge aqui um curioso indício de que as próprias redes sociais podem ser um mecanismo para o combate do agir estratégico de grupos de interesse que intoxicam a mídia tradicional, ainda que essas mesmas redes não estejam imunizadas contra essas intervenções negativas.

15 Esta crítica é levantada por Eduardo Bittar e Guilherme Almeida (2015, p. 814-815) com suporte em Tércio Sampaio Ferraz Júnior. Ambos os autores consideram que o grande volume de informações presente na rede, ainda que aproxime um maior número de pessoas, reduz drasticamente a qualidade da própria informação. De fato, é uma crítica que precisa ser levada em conta, pois se está diante de uma norma forma de socialização. Todavia, o mote é pensar em reforços para seletividade daquilo que será absorvido. A despeito da afirmação feita por Bittar quanto ao enfraquecimento da situação ideal de fala, na verdade, este estudo compreende o contrário: é que as mídias sociais possibilitam que pessoas antes excluídas tenham acesso ao debate naquela arena virtual.

16 Uma maneira de encarar essa perspectiva reside em compreender o fenômeno da identidade virtual dos sujeitos, as quais estão correlacionadas com a imagem social da pessoa, da maneira que é manifestada nas redes sociais e que deve gozar de integral proteção estatal no conspecto dos direitos fundamentais e, consequentemente, nos direitos de personalidade (BLOTA, 2013, p. 414).

17 Aqui pode ser rememorado o conflito entre o sistema poder/dinheiro e a autonomia comunicativa das esferas públicas (HABERMAS, 1997, p. 96-97). Da mesma forma que a esfera pública não está imunizada plenamente a 
No sentido das contribuições das redes virtuais para o fluxo comunicativo da sociedade, podem ser destacadas a integração dos povos, eliminando as fronteiras existentes no "mundo real", ${ }^{18}$ o aumento da visibilidade e da publicidade de dados e informações ${ }^{19}$, fazendo ruir os monopólios informacionais; a ampliação do pluralismo cultural e do acesso à cultura; a possibilidade de o cidadão acessar uma esfera pública mundial; a maior celeridade na troca de ideais, invenções e pesquisas ${ }^{20}$; e a diminuição de custos para acesso à informação. ${ }^{21}$

Essa democracia virtual se mostra vital para pressionar o poder público na consecução dos objetivos compartilhados pela coletividade cidadã, fazendo com que lideranças políticas passem também a participar desse intercâmbio informacional, mantendo-se atentas ao que é projetado nas redes sociais. Blota (2013, p. 413) ao reconhecer a similitude entre as redes sociais e o modelo de esfera pública descrito por Habermas, assinala que as próprias redes sociais já influenciaram a derrubada do governo egípcio em 2011.

As redes sociais são o teatro ${ }^{22}$ contemporâneo, que rompem com a barreira do público e do privado, pois conferem publicidade às necessidades e histórias que antes não tinham qualquer reconhecimento ou visibilidade. Com essa dinâmica, questões de grupos marginalizados, outrora excluídas das esferas públicas mais tradicionais ganham a oportunidade de serem debatidas e gerar influência política (TURSI, 2012, p. 29-30).

Ainda que desempenhe função positiva, as redes sociais contemplam alguns riscos, a exemplo de dar voz a sentimentos negativos e discursos de ódio (BLOTA, 2013, p. 416-417) o que pode acabar ferindo, por via transversa, aqueles mesmos grupos estigmatizados. De igual maneira, a esfera pública virtual também pode ser empregada pelo Estado como forma de buscar um diálogo com o cidadão, a exemplo do portal e-Democracia criado pela Câmara dos Deputados em 2009 (OLIVEIRA, 2012, p. 226).

influências de ação estratégica - ou egoística, as redes virtuais também não estão blindadas ao que não se faz relevante - ou, utilizando uma linguagem coloquial, o dito "besteirol".

18 Mundo real designa a realidade concreta, enquanto mundo virtual atine as atividades desempenhadas por intermédio da internet.

19 Podem ser categorizados aqui desde motores de busca como Google e Duck Duck Go ou, até mesmo, enciclopédias virtuais como a Wikipédia.

20 Destaque aqui para as diversas revistas científicas que publicam trabalhos acadêmicos de relevância nas mais diversas áreas.

21 A lista foi adaptada da obra de Eduardo Bittar e Guilherme Almeida (2015, p. 815-817). Os autores também elencam outros pontos negativos além dos já tratado no corpo do texto e em notas anteriores, complementando com novos itens, a exemplo da poluição informacional; o terrorismo e a guerra digital e a insegurança na administração de informações.

22 Durante o século XVIII os cidadãos frequentavam os teatros e lá encontravam uma esfera pública propícia para a troca de opiniões a partir da racionalidade comunicativa da arte. Por isso a metáfora arquitetônica descrita por Habermas em seus estudos originários (TURSI, 2012, p. 26). 
Dito isso, a tecnologia tem papel fundamental em conectar os cidadãos e superar algumas das diferenças e entraves que existem na atividade comunicativa-deliberativa, construindo um caminho para efetivação daquilo que outrora foi disposto por Jürgen Habermas em sua obra "Direito e democracia".

\section{Conclusões}

No intento de compreender o fenômeno das redes sociais à lume da filosofia política, o estudo traçou a evolução histórica da esfera pública, enquanto instituto chave para alcançar o objetivo pretendido. Na atualidade, a esfera pública se conecta com a democracia e com os direitos fundamentais, sendo um componente dos direitos políticos. É pela esfera pública que o cidadão faz valer sua autodeterminação política em face do Estado, levando ao conhecimento estatal as demandas normativas da sociedade.

A evolução histórica da esfera púbica partiu de uma expressão da liberdade individual na antiguidade clássica para um terreno fecundo para discussão das questões seculares no período medievo. Com a ascensão do liberalismo, a esfera pública radica sua legitimidade em uma autonomia privada do sujeito, com fortes conteúdos de paternalismo legal, no qual o Estado dita o que é melhor ao cidadão. Ainda no transcurso histórico, a esfera pública também já foi associada às abordagens comunitaristas, com subjugação das minorias e prevalência das maiorias.

Considerando a necessidade de pensar a democracia relacionada com a esfera pública, a investigação adotou como base teórica a obra de Jürgen Habermas, a qual permite uma terceira via, situada na autonomia política do cidadão, possibilitando o diálogo entre as autonomias privada e pública. Habermas lança bases para uma cidadania ativa, que pensa e discute problemas a partir da trivialidade da vida privada de cada um e da maneira que tais questões reverberam no cotidiano.

A comunidade passa a construir comunicativamente as soluções para os problemas encontrados e, por intermédio de uma opinião pública procedimental, a qual surge das diversas esferas públicas, leva ao crivo do Estado, o qual deverá atentar para as demandas que lhe são apresentadas de modo a manter a produção administrativa e normativa legítima em face do cidadão. Essa percepção trazida por Habermas permite, inclusive, dar voz a todos aqueles que se encontram na tão característica teia pluralista que carimba as sociedades contemporâneas, além de assegurar a expressão das minorias. 
Ao observar esse repertório de ideias, desponta a figura do cidadão como o verdadeiro protagonista, não somente por meio do voto, mas também da manifestação pública, como aquele que irá chancelar a produção estatal. Trazendo essas considerações para a realidade brasileira, em especial para o uso das redes sociais, é possível identificar que estas formam um canal comunicativo, tanto para a colheita, pelo Estado, de influxos comunicativos que partem da esfera pública, como também para a prestação de contas e justificativa por parte dos governantes.

Questões cotidianas e temas mais complexos também podem ser objeto de discussão, ainda que haja uma acirrada polarização, a qual é fruto de uma fundamentação originária de diferentes mundos da vida resulte em dissenso, é possível acreditar em um crescimento da esfera pública virtual ao longo do tempo. Se antes não havia tanta discussão pública sobre questões políticas, existe um potencial muito grande para o desenvolvimento emancipatório da razão cidadã.

Contudo, não se pode fechar os olhos para as corrupções comunicativas causadas por grupos de interesse que agem estrategicamente, contaminando o uso público da razão com mentiras e factoides. Trata-se do fenômeno do controle de dados na internet, do qual fazem parte as fake news e que representam hoje grande ameaça para esfera pública virtual e sua consagração enquanto novo meio político. Isso vai impor novos desafios, tanto para a filosofia política quanto para o direito na construção de soluções teóricas e práticas para a difusão de notícias falsas, pois a esfera pública tecnológica caminha para se firmar como um direito político fundamental.

\section{REFERÊNCIAS}

ARENDT, H. A condição humana. Tradução Roberto Raposo. 10. ed. Rio de Janeiro: Forense Universitária, 2007.

BENHABIB, S. Models of public space: Hannah Arendt, the liberal tradition and Jürgen Habermas. In: CALHOUN, C. (org.). Habermas and the public sphere. Massachusetts: MIT Press, 1992.p. 73-98.

BITTAR, E. C. B.; ALMEIDA, G. A. Curso de filosofia do direito. 11. ed. São Paulo: Atlas, 2015.

BLOTA, V. S. L. O direito da comunicação: uma nova teoria crítica do direito a partir da esfera pública política. São Paulo: Fiuza, 2013.

DIMOULIS, D.; MARTINS, L. Teoria geral dos direitos fundamentais. 4. ed. São Paulo: Atlas, 2012.

FRASER, N. Rethinking the public sphere. In: CALHOUN, C. (org.). Habermas and the public sphere. Massachusetts: MIT Press, 1992.p. 109-142. 
HÄBERLE, P. Hermenêutica constitucional - a sociedade aberta dos intérpretes da Constituição: contribuição para a interpretação pluralista e "procedimental” da constituição. Tradução Gilmar Ferreira Mendes. Porto Alegre: Sergio Antonio Fabris Editor, 2002.

HABERMAS, J. A inclusão do outro: estudos de teoria política. Tradução George Sperber e Paulo Astor Soerthe. São Paulo: Loyola, 2002.

HABERMAS, J. Direito e democracia: entre facticidade e validade. Volume I. Tradução Flávio Beno Siebeneichler. Rio de Janeiro: Tempo Brasileiro, 1997.

HABERMAS, J. Direito e democracia: entre facticidade e validade. Volume II. Tradução Flávio Beno Siebeneichler. Rio de Janeiro: Tempo Brasileiro, 1997.

HABERMAS, J. Mudança estrutural na esfera pública: investigações sobre uma categoria da sociedade burguesa. Tradução Denilson Luís Werle. São Paulo: Unesp, 2014.

MANIN, B. Legitimidade e deliberação política. In: WERLE, D. L.; MELO, R. S. (org.). Democracia deliberativa. São Paulo: Singular, 2007.p. 15-46.

MÜLLER, F. Quem é o povo? A questão fundamental da democracia. Tradução Peter Naumann. São Paulo: Max Limonad, 2003.

OLIVEIRA, R. S. Ciberdemocracia, ativismo digital e novas mídias: redefinições da esfera pública no século XXI. In: COSTA, M. N. (org.). Democracia, mass media e esfera pública. Minho: Centro de Estudos Humanísticos, 2012. p. 221-232.

SEGATTO, A. I. A tensão entre facticidade e validade. In: NOBRE, M. TERRA, R. (org.). Direito e democracia: um guia de leitura de Habermas. São Paulo: Malheiros, 2008. p. 37-54.

SILVA, F. G. A solidariedade entre público e privado. In: NOBRE, M. TERRA, R. (org.). Direito e democracia: um guia de leitura de Habermas. São Paulo: Malheiros, 2008. p. 91-116.

TURSI, A. Theatre and festival the transformations of the public sphere in the time of web 2.0. In: COSTA, M. N. (org.). Democracia, mass media e esfera pública. Minho: Centro de Estudos Humanísticos, 2012. p. 25-34. 